\title{
Integrated Façade System for office buildings in hot and arid climates: A comparative analysis
}

\author{
Yahya Ibraheem ${ }^{1}$, Poorang Piroozfar ${ }^{1}$, Eric R. P. Farr ${ }^{2}$ \\ ${ }^{1}$ School of Environment and Technology, University of Brighton, Brighton, BN2 4GJ, United Kingdom \\ ${ }^{2}$ NONAMES Design Research Foundation, 1249 F Street, San Diego, CA 92101, USA
}

Keywords: Integrated Façade Systems, Photovoltaic Shading Devices, Building Simulation, Office Buildings, Hot and Arid Climate.

\begin{abstract}
High solar gain in hot and arid climates, causes overheating in summer and increases the demand for air-conditioning, energy and carbon footprints of buildings. There are different strategies, tools, and solutions to address this problem, but Integrated Façade Systems (IFS) - façade systems where different technological solutions are integrated to improve performance and to lower the impact of the building - are still an under-developed yet a fast-growing field of research. Such systems can reduce solar heat gain, lower air conditioning costs and lessen glare, while maximising the use of natural light and help produce energy if combined with PV technology. Previous research has addressed one or a combination of some of the influential factors on performance of such systems, yet there still is a gap in the state-of-the-art research in comprehensive systematic approach not only to help gauge the impact of alteration of parameters on the IFS performance, but also an approach which can be deployed in other studies where the focus is on façade systems. With a special reference to office buildings in hot and arid climates, this paper sets out to systematically identify IFS parameters which have potential impacts on energy, lighting, glare and heat gain. Then as a part of a comprehensive ongoing research in this area, this paper presents a proof-of-concept to demonstrate the application of such methodology to a parametric study of IFS technology. In doing so, it chooses only one of the parameters indicated in this systematic review and uses building simulation as its core method to investigate the influence and impacts of those variations on performance of IFS. It will indicate how this approach provides high flexibility to adjust or configure any combination of those parameters and to measure, subjectively, how this will result in change in façade performance.
\end{abstract}

\section{INTRODUCTION}

The integrated design has been gaining momentum in built environment and architectural design over the past two decades and façades are no exemption and as such have witnessed major technological improvements in this regard. Integrated Façade Systems (IFS) - systems where different technological solutions are integrated to improve performance and to lower the impact of the building - are a fast-growing field of research with broad scope for application and significant positive impact on the environment. Such systems can reduce solar heat gain, lower air conditioning rates and lessen glare, while maximising the use of natural light. The technological solutions used in IFS can broadly be classified under three components: 1) High-performance Glazing (HPG), 2) Shading Devices (SD) and 3) Integrated Photovoltaics (IPV). Moreover, the literature on these systems in fully- or highly-glazed buildings is scarce and even more so for non-residential buildings or buildings in hot and arid climates. When considering IFSs, shading devices can be considered as an effective part of 
the façade components that plays a significant role in reducing the negative impact of the solar radiation (in the form of heat gain) and help provide an acceptable indoor condition. However, solar radiation can be harvested using Photovoltaic (PV) cells and fed into the building itself, hence PV integrated shading devices (PVSD). Although previous research has addressed some or a combination of influential factors on the performance of such systems, there still is a gap in the state-of-the-art that is a comprehensive and systematic approach to gauge the impact of alteration of parameters on the IFS performance, with full potential to help best configure such solutions for different design contexts. This paper aims to establish and demonstrate the application of the systematic approach to the evaluation of the performance of integrated facade systems. To fulfil this aim, this paper sets out to contribute to the knowledge in the field by answering the research questions as follows:

- Can integrated facade systems contribute to a more environmentally-concerned approach to the design of buildings? What are, if there is any, benefits of such integration? And how can they be adjusted, calibrated or configured to maximise those benefits?

To achieve that aim this study attempts to provide data using building simulation as the main method and is aimed at offering a systematic approach to enhance the built environment in developing economies with a research prospect that investigates the influence of those parameters for further in-depth study to achieve the optimum trade-off between the livable indoor environment, energy consumption, and carbon footprint.

\section{LITERATURE REVIEW}

As a part of the façade components, shading devices play a significant role in reducing the heat gain and providing acceptable indoor conditions (Alzoubi and Al-Zoubi, 2010). Although the application of PV in buildings was introduced in the late 1970s, it was first characterised as a building integrated component in late 1990s (Patankar, 2010) and it was not until 1998 that Yoo and Lee proposed, most probably for the first time, integrated photovoltaics as shading devices. Combining external solar shading devices and photovoltaic panels has many advantages (DGS, 2008), such as generating green energy which reduces the use of fossil fuels as well as adding architectural features specific to the design of shading devices when combined with photovoltaic panels. However, the application of PVSD has significant challenges due to the complexity of the system and the adaptability of these systems to different contextual conditions (Lee et al., 2009). Nevertheless, it is important to note that integration of PV panels, what is commonly known as 'Building Integrated Photovoltaic' or BIPV, is not limited to shading devices only. They can be integrated into any part of the building that can potentially receive a considerable amount of solar radiation like windows, claddings, skylight as well as external shading devices (BCA, 2008).

Photovoltaics as shading devices (PVSD) are usually an external building skin layer that can be applied independently in both new and existing buildings. This technology has the dual advantage of generating electricity directly from the incident sunlight and the normal function of external shading devices in protecting the building from overheating, providing visually comfortable interior space and save energy (Zhang, 2014, Kang et al., 2012). They have proven technical advantages over other types of PV installations like roof stand-alone PV systems (Mandalaki et al., 2014a). Advantages include ease of maintenance, ease inspection, allowing the roof space for other uses and higher possibilities to integrate kinetic technologies that can track the sun while acting as an interactive solution for optimising solar gain throughout the year. In order to appropriately apply this technology into a 
building, it is essential to highlight the main influential parameters that affect the performance of buildings with PV shading devices to be able to systematically and comparatively investigate the impact pertaining to adjustments of such parameters. These parameters include but are not limited to building geographical location (Bahr, 2013), building orientation (Yoo and Manz, 2011), type of shading devices (Mandalaki et al., 2012), inclination angle of louvers (Hwang et al., 2012) and the dimensions of the louvers (Kang et al., 2012), to name a few.

The comprehensive critical review of the literature led to classifying the existing state-ofthe-art into three systemic levels divided into three categories i.e. 'design considerations and configurations', 'performance aspects' and 'assessment methods'. This systemic approach was then used as a methodological framework for this study. To be able to stay within the limits, the second two categories i.e. 'performance aspects' and 'assessment methods' will not be reviewed in this paper and the development of the methodological approach has not been included in this paper but the approach itself will be explained in the next section (Please see Figure 3).

\section{Design considerations and configurations}

Studies concerned with design consist of two different sub-categories i.e. design considerations and design configurations. Design considerations are the factors over which there is limited to no control but they need to be taken into account when the design process of building or the course of façade is being carried out. Design configurations, by contrast, are those elements which can be adjusted, changed or manipulated by the designer and are accounted for as a part of the project that can be shaped by the design process.

At context level, latitude and geographical location with a direct impact on solar radiation, temperature, sky conditions and other climatic parameters as a means to determine type and dimensions of shading (Bahr, 2009), optimal design option (Bahr, 2013) were pointed out. Relative layout of the roads to the building shape (Di Vincenzo et al., 2010), diffuse radiation and its correlation with urban design to help decide where to install PVSDs to maximise electricity generation (Tongtuam et al., 2011) were also studied with some others looking into the effect of architectural and technical aspects of the PVSD to predict their performance at urban scale using GIS (Karteris et al., 2014).

At building level, although not commonly agreed down to the detailed levels, orientation is still considered as a key determinant to optimise PV shading devices (Bahr, 2009, Bahr, 2013, Kang et al., 2012, Yoo, 2011). Building function such as weather proofing, noise reduction, shading, flexibility, transparency, colour, and texture can be affected by the application of PVs include (Vassiliades et al. 2014) with the building type and the proposed PV solutions impact on potential architecturally suitable area of a façade which was investigated by Karteris et al. (2014).

At envelope level, variations were studied by Youssef et al. (2015) where a tool was developed, under a specific climate condition for a specific building type. One of the most influential parameters determining the PVSD's performance is the angle of inclination; that helps ensure an optimum value for both internal solar gain control and electric generation (Bahr, 2013, Hwang et al., 2012, Kang et al., 2012, Kim et al., 2014). Probably one of the most worked over from different perspectives, yet still one of the least agreed upon areas at 
envelope level, is the tilt angle of the PV panels (Bahr, 2009, Bahr, 2014, Hwang et al., 2012, Jung, 2014, Kim et al., 2010, Yang and Lu, 2005). The size and dimension of the PV panels are also effective parameters that have been the focus of several studies (Kang et al., 2012, Mandalaki et al., 2014b, Sun and Yang, 2010, Mandalaki et al., 2012) along with distance between louvres and their depth (Bahr, 2009, Bahr, 2014, Hwang et al., 2012), and the problem of over-shading (Yoo and Lee, 2002).

In many occasions, a clear link between the parameters at different systemic levels is quite evident.

\section{RESEARCH DESIGN AND METHODOLOGY}

This study is divided into two stages. The first stage outlines, very briefly, the approach developed for this research to facilitate systematic investigation of the influential factors and the second stage provides a proof of concept by simulating a subset of combinations of possible configurations to demonstrate how this study works and to set the scene for rolling out a fully-fledged investigation of all possible combinations of such parameters and their impacts on energy and indoor comfort conditions.

This paper utilises a methodology where the topic is looked into through systems theory. The idea of the building as a system was derived from modern systems theory and the application of building science to building performance (Kesik, 2014). Piroozfar (2008) investigates the building envelope as 'the system', the building as 'the super-system' and the façade components as 'the sub-system' to investigate the trade-offs in mass customisation of envelope systems using off-site production methods; what has then been further developed to investigate the application of BIM for a fully customisable façade system by Farr et al. (2014). A slightly different approach has been used for this study to also include the contextual determinants to facilitate a global systematic approach to the concept of IFSs. This study takes the building as 'the system', the context as 'the supersystem', and the façade as 'the sub-system' (Figure 1). This triad systemic classification can and may be expanded further into next lower level which includes the façade components if and when a closer, more detailed investigation would be needed. This methodological approach has twofold benefits both at theory and practice level. It can facilitate not only the study of the literature on the topics related to that of this research but can also help classify their impacts and further enables the decision support for the course of intervention/ action when it comes to the proposition of solutions for practical applications of building façades design.

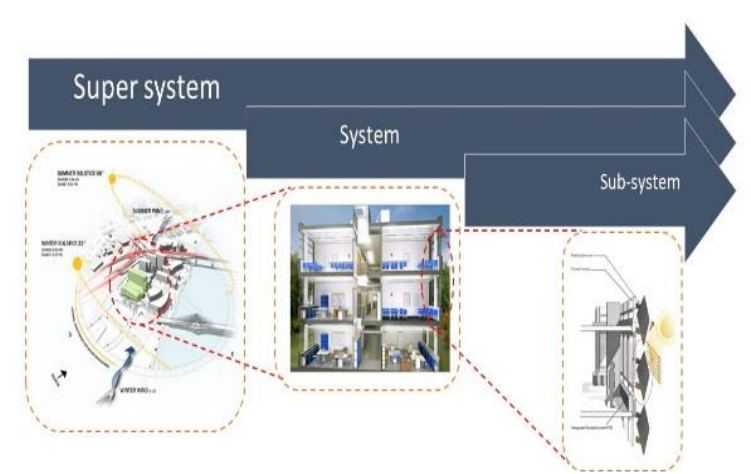

Figure 2 Systematic approach developed for this study

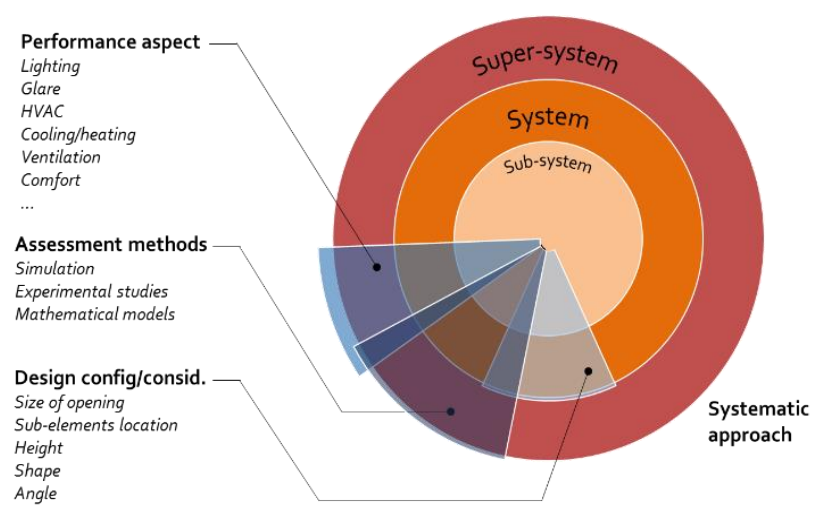

Figure 1 Identified categories in the literature superimposed on the systematic approach 
The literature identified three main categories (Figure 2) - design configurations and considerations, performance aspects and assessment methods - under which it clustered existing literature on PV integrated shading devices at three different systemic levels, i.e. super-system: context level, system: building level and sub-system: façade level. Design considerations and configurations are considered (Figure 3).

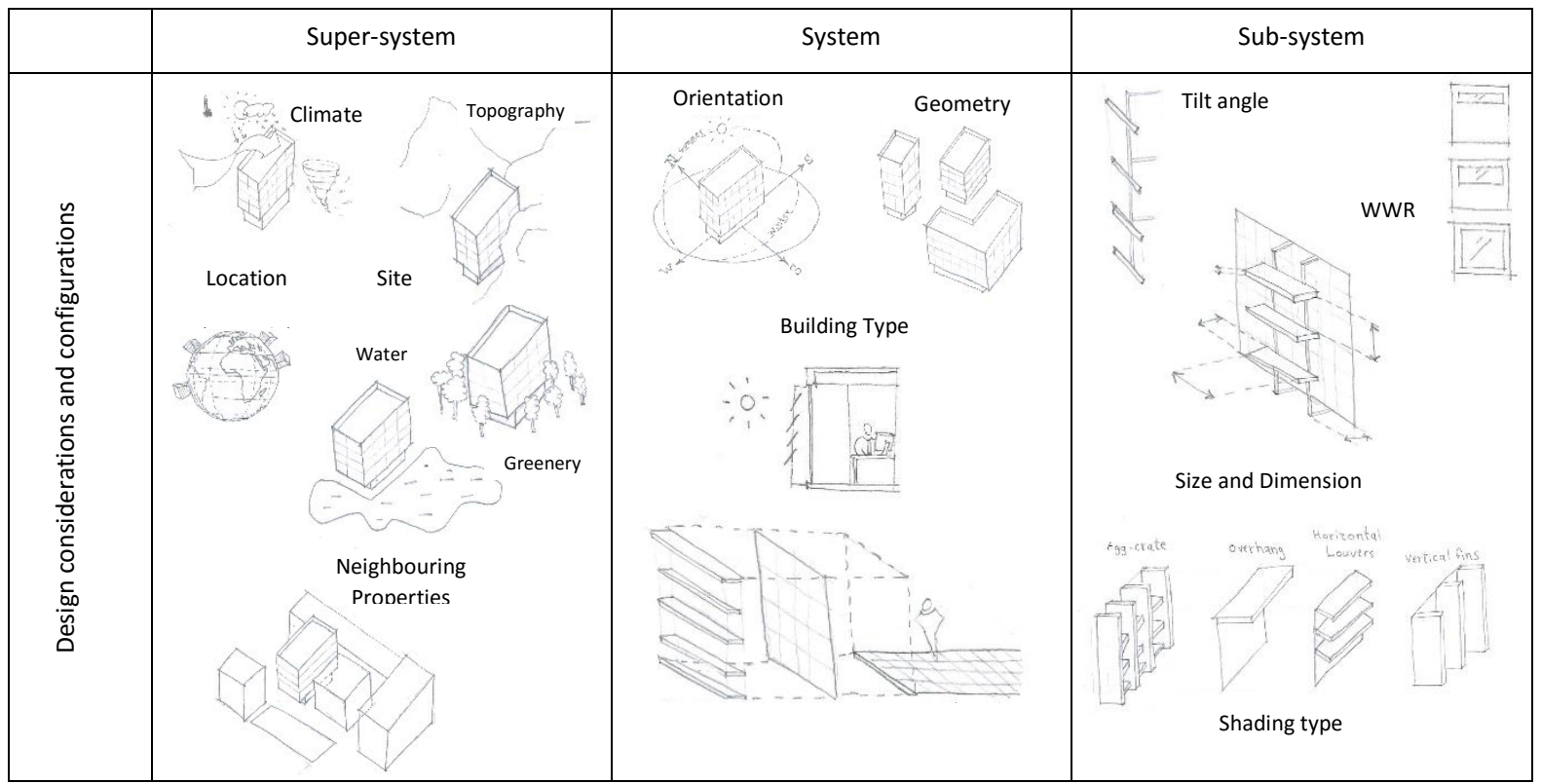

Figure 3 Design considerations and configurations

Findings in the literature, which are related to the chosen factor, feed into the simulation to assess whether sensible results have been achieved or not. If it was proven to be meaningful, the investigations will be carried on. Otherwise, alteration of contextual conditions will be applied.

\section{DATA GENERATION FOR THE PROOF-OF-CONCEPT CASE}

An industry standard application for dynamic building performance analysis, IES-VE, which has been rigorously tested and validated against real-life scenarios was chosen for carrying out simulations for this study. Built-in components of IES-VE: MODELIT, SUNCAST, APACHESIM and FlucsDL were used for: building up the model, shading calculations, dynamic thermal simulation and daylighting analysis, correspondingly.

\section{Modelling process in IES-VE and simulation}

Weather data file for Baghdad city $\left(33^{\circ} 13^{\prime} \mathrm{N}, 44^{\circ} 13^{\prime} \mathrm{E}\right)$ was utilised for this simulation. Simulations were conducted for the whole year to determine the peak months of total energy consumption and solar gain. To be able to observe the sole impact of changing the angle of inclination, no internal thermal gain or occupants profiles were applied at this stage. Then construction materials were assigned to the building elements. The daylighting analysis was carried out using $\mathrm{CIE}$ standard clear sky condition in order to consider the impact of the application of shading devices in all scenarios. To ensure that the simulations are carried out in the most appropriate way, all other variables except for inclination angle of the louvers were kept constant throughout all simulations. Figure $4 \mathrm{~A}$ shows the base case and Figure $4 \mathrm{~B}$ shows the case study with shading devices which was used to simulate performance under different inclination angle. 


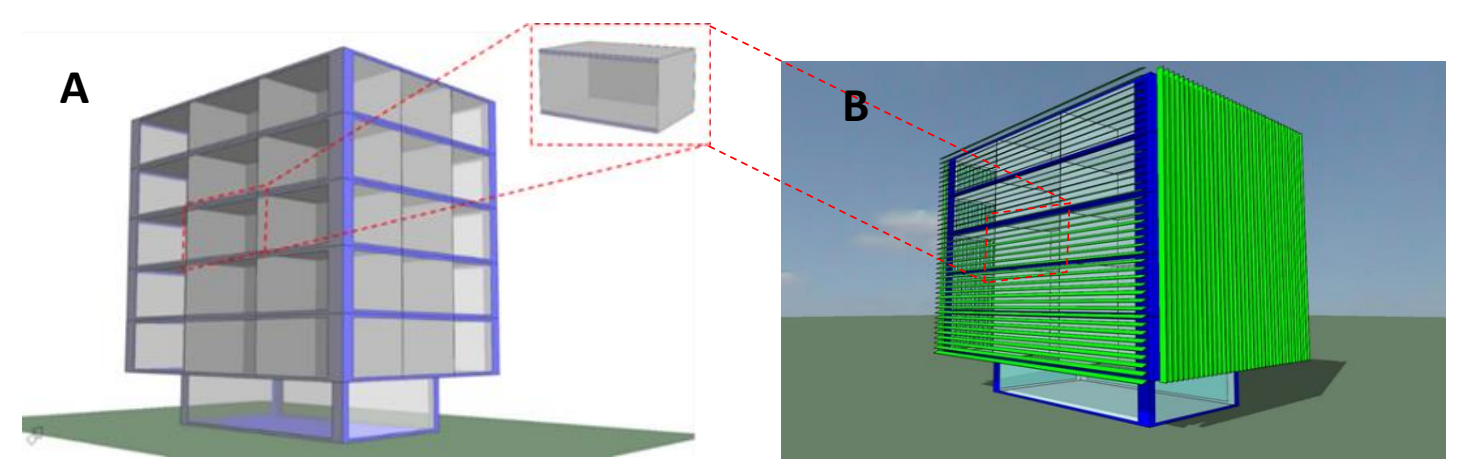

Figure 4 Developed model for this study

\section{Details of the model}

A simple six-story office building with an area of $436 \mathrm{~m} 2$ per each floor divided into nine

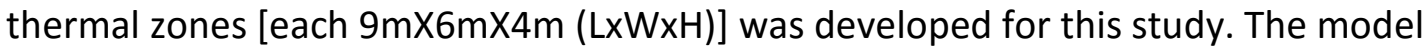
represents a significant sample of office buildings in Iraq. The overall opening (i.e. windows) is defined in a form of a percentage of glass to the overall external envelope of the building, otherwise known as Window-to-Wall-Ratio (WWR) as of $80 \%$ for highly-glazed buildings. In this model, the reflectance of the material used was set to 0.85 for the ceiling, 0.65 for the walls and 0.20 for the floor. Details of the model are shown in Figure 5.

External shading devices were also defined by ModelIT. These devices are defined based on specific characterisation on the module (IESVE, 2014). The distance between the louvers and the main façade and between the louvres are both $0.5 \mathrm{~m}$, and the depth of the louvres is also $0.5 \mathrm{~m}$. The louvers cover the full length of the façade. All surfaces of the office unit are considered to be adiabatic. Air conditioning and artificial lighting were not used and the average of daylighting above the minimum illuminance level of 500 LUX was calculated for each case. The glazing type is single glazing with a U-vale: 5.1742 , Tvis: 0.76 and SHGC: 0.9549 .



A

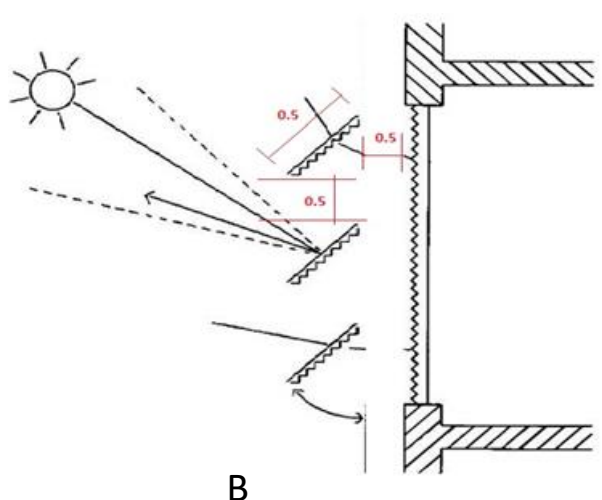

B

Figure 5 Details of the model

\section{DATA ANALYSIS}

A base case scenario was first simulated to provide a benchmark as the worst possible scenario against which improvements could be measured. In this case, no shading devices were applied on a façade with an $80 \%$ of WWR where one thermal zone was simulated. The day selected for the simulation was 15th of June as suggested to be the highest average on record for Iraq based on CLIMATEMPS (2015). The alternative scenarios were simulated where horizontal louvers were applied to south-facing façade and vertical louvers were applied to east- and west-facing facades. The horizontal inclination angle of the louvers on 
the south-facing façade was set to $0^{\circ}, 25^{\circ}$ and $60^{\circ}$ as suggested by Bahr (2013) while the louvers on both the east and west-facing facades were kept unchanged. The results were assessed based on the influence of this calibration on solar gain and the monthly cooling plant sensible load. Analysis of the first run of simulations is as follows:

\section{Solar heat gain, the first run}

Amongst all 4 simulated cases [the base case and the three selected inclinations as suggested by Bahr (2013)], the highest solar gain was observed in the base case as expected where no shading devices were applied. When applying shading devices, a sharp decrease of solar gain was observed between the base case and the $0^{\circ}$ inclination. Then a less significant decrease was observed from $0^{\circ}$ inclination onwards. The decrease between $25^{\circ}$ and $60^{\circ}$ inclination is less than the decrease between $0^{\circ}$ and $25^{\circ}$ inclination as shown in Figure 6. This observation is not as significant as suggested by Bahr (2013).

\section{Cooling loads, the first run}

There is a significant difference in the percentage of the monthly cooling loads compared to the base case. However tilting the angle to $25^{\circ}$ and $60^{\circ}$ was also not having as significant effect as suggested by Bahr (2013). A shift of the peak load was observed when the peak load changes from early August back to early June once shading devices on the south-facing façade were applied. Altering the inclination angle has clearly affected the cooling loads. During moderate seasons, a significant reduction was observed in all cases in comparison with the base case. However, $0^{\circ}$ inclination has not brought the cooling load down to zero during the cold season compared to other inclination angles, i.e. $25^{\circ}$ and $60^{\circ}$. During the hot season (April-October), the load was slightly different even though the inclination angle was kept unchanged or inclined to $25^{\circ}$ and $60^{\circ}$ (Figure 7).

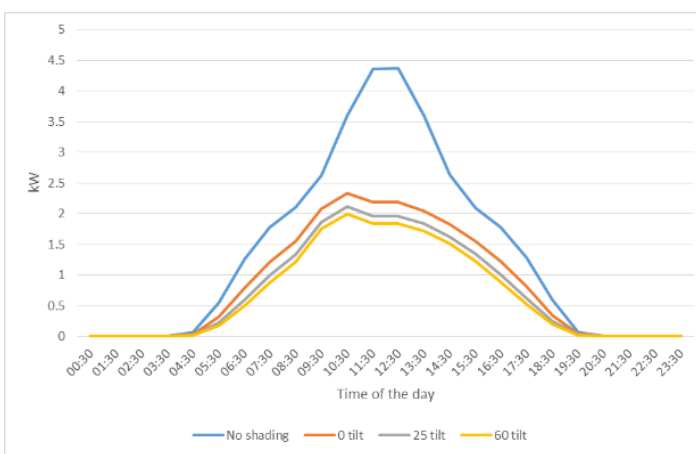

Figure 6 Solar gain in the studied room on 15 June (first run)

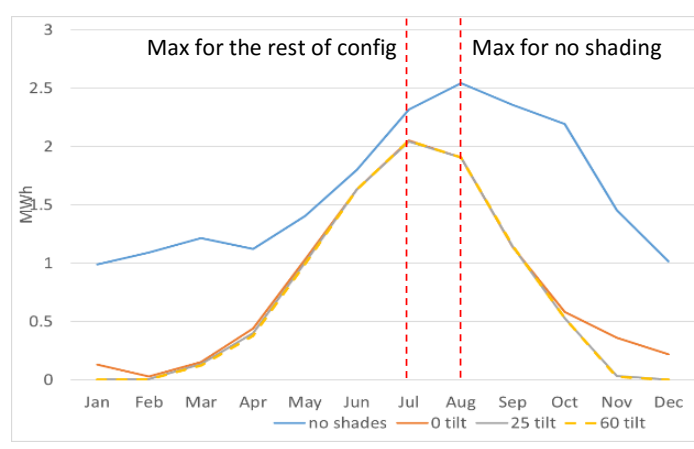

Figure 7 Cooling plant sensible load (first run)

This effect is due to the low sun angle during moderate and cold seasons on the south façade. Therefore, further investigations to include heating loads as well is needed. On the system level (or the building level), the effect of modifying the inclination angle of horizontal shading devices on the south-facing façade can also be confirmed by looking at the results of the yearly cooling plant sensible load. Significantly high percentage of the yearly cooling plant sensible load was observed in the base case. This was significant as expected.

A significant improvement in the cooling load for the user room was observed when shading devices with $0^{\circ}$ inclination were applied compared to the base case where yearly figures were reduced by up to $50 \%$. However, the reduction in the cooling load was not significant when changing the inclination angle to $25^{\circ}$ and $60^{\circ}$ where the cooling load levelled off 
(Figure 8). Therefore, the next step will be adding more variations of inclination angle as suggested by other literature as opposed to Bahr (2013).

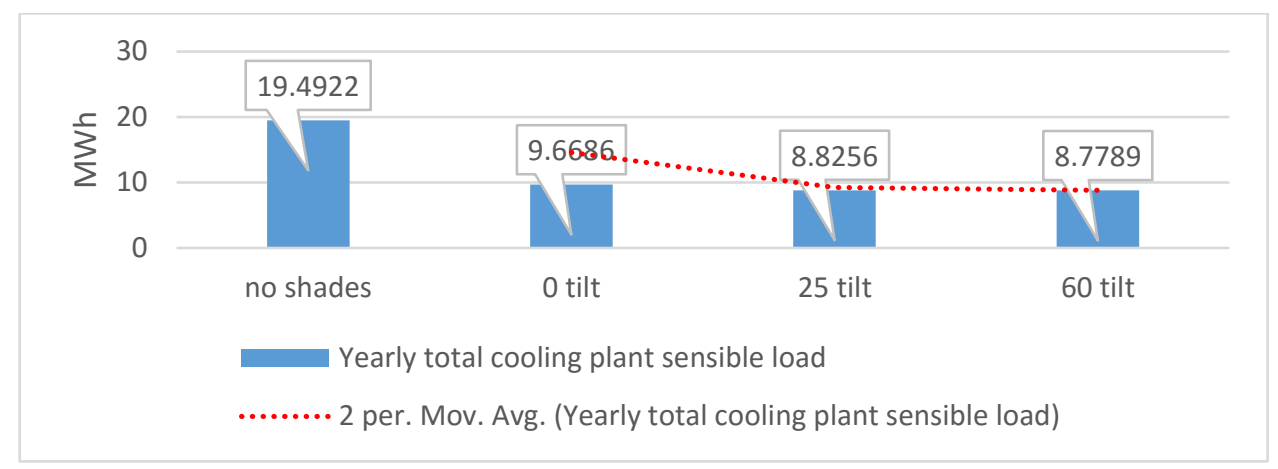

Figure 8 Cooling plant sensible load-yearly totals (first run)

The second run of analysis was attempted on by further developing on the findings of literature. Sun et al. (2012) suggest that the optimum inclination angles for different designs vary from $30^{\circ}$ to $50^{\circ}$. Since the simulated angles were 0,25 and 60 , it is reasonable to provide variations that cover the possible values of the inclination angles spectrum. Therefore, the angles that will be simulated are $15^{\circ}, 45^{\circ}$, and $80^{\circ}$.

\section{Solar gain, the second run}

Amongst the simulated cases in the second run of simulations, a less significant change in the trend of the decrease of solar gain was observed in reference to the first run of simulation results (Figure 9).

\section{Cooling loads, the second run}

Figure 10 shows that there is hardly any difference in the cooling load between the additional simulated angles. Moreover, when combining all the results, it can be seen that there is no significant change between all alterations $\left(15^{\circ}, 25^{\circ}, 45^{\circ}, 60^{\circ}\right.$ and $\left.80^{\circ}\right)$ compared to $0^{\circ}$ inclination. In addition, these alterations have considerably reduced the cooling loads during the moderate season and have brought down the load down to zero during the cold season in comparison to $0^{\circ}$ inclination.

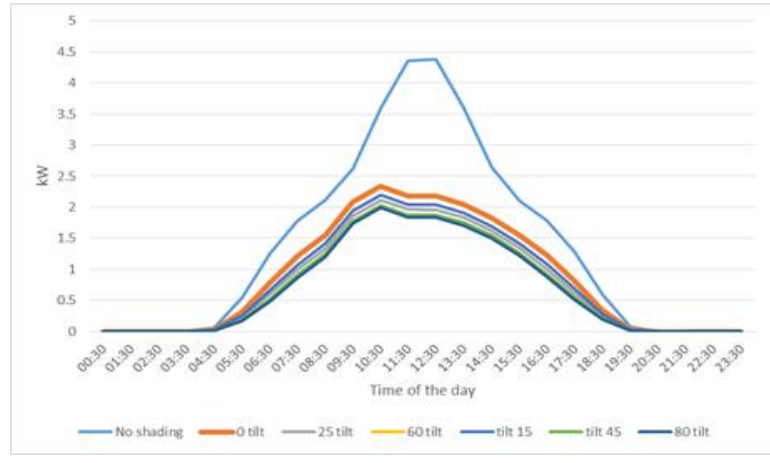

Figure 9 Solar gain in the studied room on 15 June (second run)

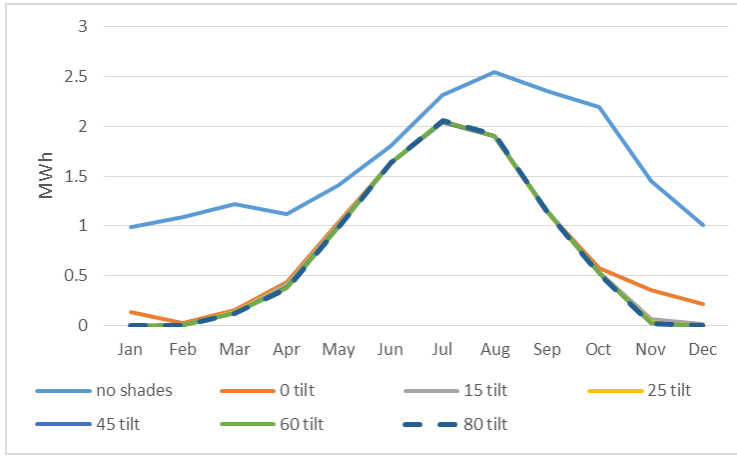

Figure 10 Cooling plant sensible load (second run)

The results from the first run of simulation can also be substantiated when combining them with the results of the second run of simulations. The same pattern was observed in the 
total yearly cooling plant sensible load for all simulated cases (Figure 11). However, a slight increase in the load was observed in the case of $80^{\circ}$ inclination which represents a fluctuation in the trend.

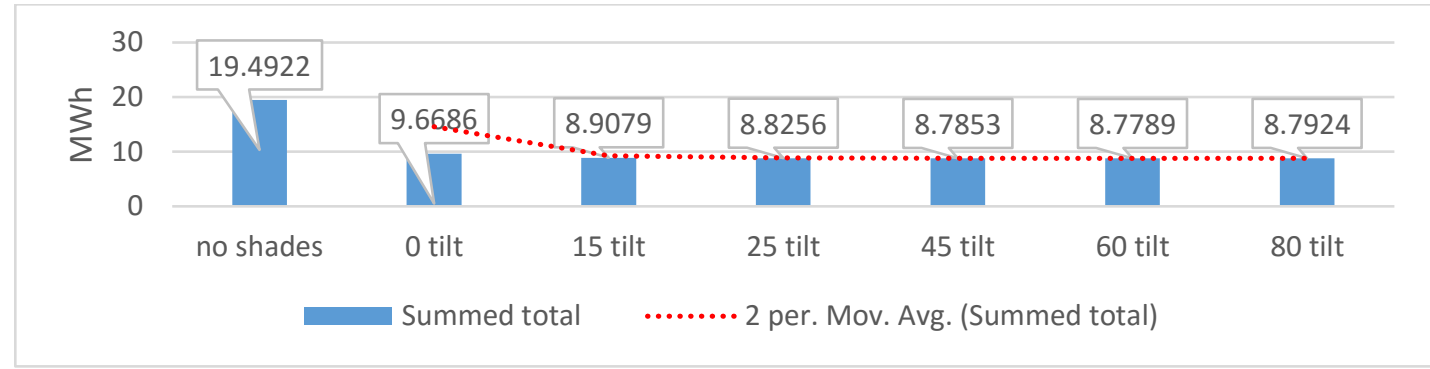

Figure 11 Annual summed cooling plant sensible load for all simulated cases

\section{Daylighting analysis}

The average illuminance of user room in question was calculated for all cases on the same design day of $15^{\text {th }}$ June at the midday $(12: 00 \mathrm{pm})$ using FlucsDL. It can be seen that there is a steady decrease in the average daylight. In the base case, the average daylight was 1350 LUX which exceeds the minimum average illuminance for office spaces that is 500 LUX (ASHRAE reported in $\mathrm{O}^{\prime}$ Connor et al., 2013). However, from $15^{\circ}$ up to $60^{\circ}$ a significant reduction of daylight can be observed due to changes in inclination angle where the space between two louvers is reduced, thereby reducing the daylight passing through to internal space. The case with $80^{\circ}$ angle is the worst case where artificial lighting will be inevitable resulting in additional energy consumption not only because of the energy required for the artificial lighting itself but also for the additional heat generated as a result of that. Figure 12 shows average daylight available in the simulated user room on $15^{\text {th }}$ June at 12:00 pm.

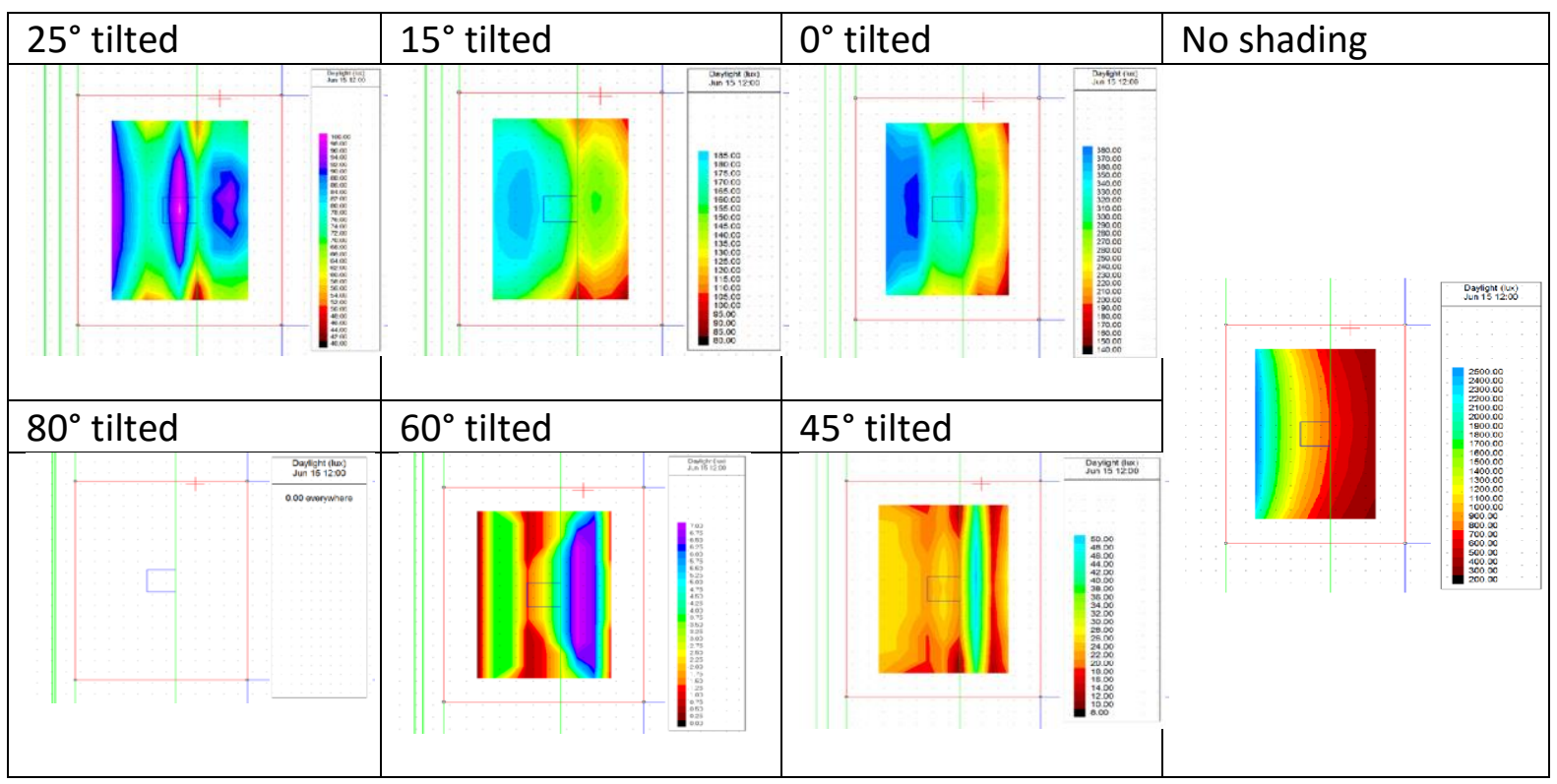

Figure 12 daylight analysis of user room

Figure 13 shows average illuminance in LUX for all 7 simulated cases. 


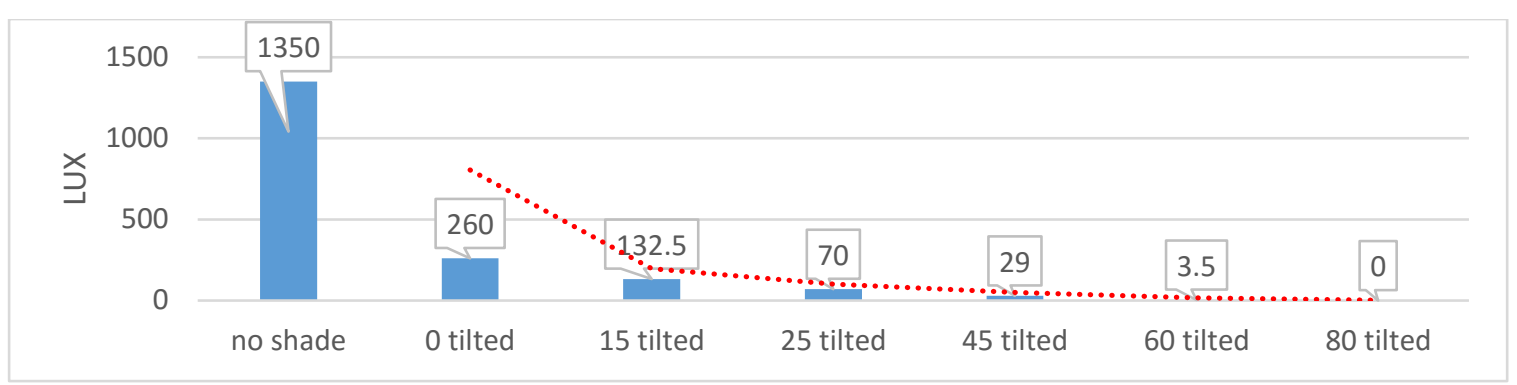

Figure 13 average illuminance in LUX for the simulated cases

\section{DISCUSSION OF FINDINGS AND CONCLUSIONS}

Preliminary results of two rounds of simulation were presented where the analysis begins with establishing the scenarios to be simulated. A single variable - the inclination angle of horizontal louvers - was chosen to be adjusted and compared to the base case while the rest of the parameters were kept unchanged. The input used from the literature were $0^{\circ}$, $25^{\circ}$, and $60^{\circ}$ for the first run and no significant changes between angles above $0^{\circ}$ were detected. Therefore the second run of simulation with $15^{\circ}, 45^{\circ}$, and $80^{\circ}$ was carried out to investigate the effect of a change in angle in more details. The consequences of each modification were evaluated based on solar gain, cooling load and natural daylighting as assessment criteria as suggested in the literature. Some of the findings were sensible as suggested by the literature whereas others were not. A shift of the peak cooling load was observed between early August and early June once shading devices on the south-facing façade were applied. Altering the inclination angle clearly affected the cooling loads. During moderate seasons, a significant reduction was observed in all cases in comparison with the base case. However, $0^{\circ}$ inclination has not brought the cooling load down to zero during the cold season compared to other inclination angles. During the hot season (April-October), the load was slightly different for $0^{\circ}, 25^{\circ}$ and $60^{\circ}$. The alteration of the inclination angle was found to have a considerable impact on reducing the availability of daylighting which may cause an increase in the energy use. This increase is due to additional artificial lighting and additional cooling loads that the artificial lighting will add. All angles show a significant reduction in daylighting especially 60 and above, which nearly blocked the light.

The results of this study showed that it is possible to carry on with full-scale investigations as the approach and the expected outcomes were sensible and meaningful. Detailed additional contextual conditions will be used from the literature to inform the recalibration of the input for simulation. The angles tested at this stage will be used as the basis for the next stage of simulations where other parameters will be added to configurations. The results can help narrow down the number of simulations in the next stages. The major third function of IFSs - electricity generated by the PVSD, which will be calculated in the next stage, is expected to provide a counter-balance parameter with which the full if-then scenarios of this research can be further probed.

Future research will develop a combination matrix to include all possible façade configurations and the simulations for each scenario will be carried out. Results will provide optimised models and guidelines on the practical level with detailed analysis and expected performance/saving. 


\section{ACKNOWLEDGEMENT}

This research has been sponsored by Iraqi Ministry of Higher Education and Scientific Research.

\section{REFERENCES}

ALZOUBI, H. H. \& AL-ZOUBI, A. H. 2010. Assessment of building façade performance in terms of daylighting and the associated energy consumption in architectural spaces: Vertical and horizontal shading devices for southern exposure facades. Energy Conversion and Management, 51, 1592-1599.

BAHR, W. 2009. Integration of shading devices and photovoltaic panels into existing building facades. Green Retrofit conference. Dubai Knowledge Village.

BAHR, W. 2013. OPTIMAL DESIGN PARAMETERS OF THE BLINDS INTEGRATED PHOTOVOLTAIC MODULES BASED ON ENERGY EFFICIENCY AND VISUAL COMFORT ASSESSMENTS. Central Europe towards Sustainable Building 2013. Prague.

BAHR, W. 2014. A comprehensive assessment methodology of the building integrated photovoltaic blind system. Energy and Buildings, 82, 703-708.

BCA 2008. GREEN: Handbook-Photovoltaic (PV) systems in buildings, Singapore, Building and Construction Authority.

CLIMATEMPS. 2015. Climate, Average Weather of Iraq [Online]. Available: http://www.baghdad.climatemps.com/temperatures.php [Accessed 05/02/2016 2015].

DGS 2008. Planning and installing photovoltaic systems: a guide for installers, architects and engineers, London, Earthscan.

DI VINCENZO, M. C., KESTEN, D. \& INFIEL, D. 2010. Assessment of performance of building shading device with integrated photovoltaics in different urban scenarios. IEEE ICSET 2010. Kandy, Sri Lanka.

FARR, E. R., PIROOZFAR, P. A. \& ROBINSON, D. 2014. BIM as a generic configurator for facilitation of customisation in the AEC industry. Automation in Construction, 45, 119-125.

HWANG, T., KANG, S. \& KIM, J. T. 2012. Optimization of the building integrated photovoltaic system in office buildings-Focus on the orientation, inclined angle and installed area. Energy and Buildings, 46, 92-104.

IESVE 2014. ShadingDevices. Scotland: Integrated Environmental Solutions-Virtual Environment.

JUNG, S. K. 2014. Optimal Control Methods for PV-integrated Shading Devices. PhD, University of Michigan.

KANG, S., HWANG, T. \& KIM, J. T. 2012. Theoretical analysis of the blinds integrated photovoltaic modules. Energy and Buildings, 46, 86-91.

KARTERIS, M., THEODORIDOU, I., MALLINIS, G. \& PAPADOPOULOS, A. M. 2014. Façade photovoltaic systems on multifamily buildings: An urban scale evaluation analysis using geographical information systems. Renewable and Sustainable Energy Reviews, 39, 912-933.

KESIK, T. J. 2014. Building Science Concepts [Online]. National Institute of Building Sciences. Available: https://www.wbdg.org/resources/buildingscienceconcepts.php [Accessed 24/04/2016 2016].

KIM, J. J., SUNG KWON, J., YOON SEOK, C. \& JEONG TAI, K. 2010. Optimization of Photovoltaic Integrated Shading Devices. Indoor and Built Environment, 19, 114-122.

KIM, S.-H., KIM, I.-T., CHOI, A.-S. \& SUNG, M. 2014. Evaluation of optimized PV power generation and electrical lighting energy savings from the PV blind-integrated daylight responsive dimming system using LED lighting. Solar Energy, 107, 746-757.

LEE, E. S., SELKOWITZ, S. E., DIBARTOLOMEO, D. L., KLEMS, J. H., CLEAR, R. D., KONIS, K., HITCHCOCK, R., YAZDANIAN, M., MITCHELL, R. \& KONSTANTOGLOU, M. 2009. High Performance Building Façade Solutions: PIER Final Project Report. Public Interest Energy Research (PIER) Program. California , USA: Lawrence Berkeley National Laboratory. 
MANDALAKI, M., PAPANTONIOU, S. \& TSOUTSOS, T. 2014a. Assessment of energy production from photovoltaic modules integrated in typical shading devices. Sustainable Cities and Society, 10, 222-231.

MANDALAKI, M., TSOUTSOS, T. \& PAPAMANOLIS, N. 2014b. Integrated PV in shading systems for Mediterranean countries: balance between energy production and visual comfort. Energy and Buildings.

MANDALAKI, M., ZERVAS, K., TSOUTSOS, T. \& VAZAKAS, A. 2012. Assessment of fixed shading devices with integrated PV for efficient energy use. Solar Energy, 86, 2561-2575.

O'CONNOR, J., LEE, E., RUBINSTEIN, F. \& SELKOWITZ, S. 2013. Tips for daylighting with windows: the integrated approach.

PATANKAR, C. 2010. BIPV - Building Integrated Photovoltaic [Online]. Solar Energy Explorer.com. Available: http://www.solarenergyexplorer.com/bipv.html\#axzz3QnEPfHCm [Accessed 04/02/2015].

PIROOZFAR, P. A. E. 2008. Mass-customisation: The Application on Design, Fabrication and Implementation (DFI) Processes of Building Envelopes. PhD, University of Sheffield.

SUN, L., LU, L. \& YANG, H. 2012. Optimum design of shading-type building-integrated photovoltaic claddings with different surface azimuth angles. Applied Energy, 90, 233-240.

SUN, L. L. \& YANG, H. X. 2010. Impacts of the shading-type building-integrated photovoltaic claddings on electricity generation and cooling load component through shaded windows. Energy and Buildings, 42, 455-460.

TONGTUAM, Y., KETJOY, N., VAIVUDH, S. \& THANARAK, P. 2011. Effect of the Diffuse Radiation Reflection from Exterior wall on Shading Device Integrated Photovoltaic Case of Thailand building. Energy Procedia, 9, 104-116.

YANG, H. \& LU, L. 2005. The Optimum Tilt Angles and Orientations of PV Claddings for BuildingIntegrated Photovoltaic (BIPV) Applications. Journal of Solar Energy Engineering, 129, 253-255.

YOO, S.-H. 2011. Simulation for an optimal application of BIPV through parameter variation. Solar Energy, 85, 1291-1301.

YOO, S.-H. \& LEE, E.-T. 2002. Efficiency characteristic of building integrated photovoltaics as a shading device. Building and Environment, 615-623, 615-623.

YOO, S.-H. \& MANZ, H. 2011. Available remodeling simulation for a BIPV as a shading device. Solar Energy Materials and Solar Cells, 95, 394-397.

YOUSSEF , A. M. A., ZHAl, Z. J. \& REFFAT , R. M. 2015. Design of optimal building envelopes with integrated photovoltaics. Building Simulation.

ZHANG, X. 2014. Building Performance Evaluation of Integrated Transparent Photovoltaic Blind System by A Virtual Testbed. Msc, Eindhoven University of Technology. 